\title{
Assessment of Effects of Areca Nut in the Development of Oral Sub-mucous Fibrosis amongst Nursing Students
}

\author{
Erum Aftab, Erum Khan, Farah Anil, Rahmatullah Vinjhar
}

\begin{abstract}
OBJECTIVE: To analyze the effects of areca nut on oral health of nursing students.

METHODOLOGY: A descriptive cross-sectional study was conducted to gather information from nursing students. A random sample of 380 students $(n=380)$ November 2018 to January 2019. The self-structured questionnaire was employed containing items regarding usage of areca nut, reasons of chewing, effect on oral health and awareness among users and non-users. Subjects were consented and data was obtained at their respective settings.

RESULTS: There were $53.4 \%(n=203)$ male and $46.6 \%(n=177)$ female, mean age of the students was $2.09 \pm 1.13$ ranging between 16 to 40 years. The respondents identified of areca chewing habit including both genders were $82 \%(n=312)$. Subjects suffering from oral lesions after using areca nut on self-reporting were $30.3 \%(n=115)$, while the frequency of consuming areca nut made products decreases as the age's increases.

CONCLUSION: Areca nut consumption among nursing students found in both urban and rural areas whether they take it as habitual or just like its taste. Resembling other professions, nursing students also found as frequent areca nut user as habit with minimum oral health effects.
\end{abstract}

KEYWORDS: Areca nut, Betel quid, Vesicles, Blanching, and Oral sub-mucosal fibrosis.

This article may be cited as: Aftab E, Khan E, Anil F, Vinjhar R. Assessment of Effects of Areca Nut in the Development of Oral Sub-mucous Fibrosis amongst Nursing Students. J Liaquat Uni Med Health Sci. 2019;18(04):291-6. doi: 10.22442/jlumhs.191840647

\section{INTRODUCTION}

Globally areca nut has become a major challenge to the health. The young populations of developing countries are mainly targeted by the advertisement to use areca products ${ }^{1}$. This is a highly significant public issue and need daring efforts to control in reduction of areca nut usage amongst the communities.

Consequently, World Health Organization (WHO) addressed, that nearly about 600 million people use areca nut on daily basis all over the world ${ }^{2}$. Areca nut usage is targeting mostly young people after other sedative materials and amongst other cancer provoking agent areca nut is on forth number ${ }^{3}$. Pakistan is another prominent country after India in which these smokeless tobacco products so called areca nut are being used, with a frequency among Pakistani men (21.3\%) and women (19.3\%), respectively. More apparently $90 \%$ of oral cancer cases have been reported to be associated with consumption of such products, signaling to be the vital factors that trigger oral cancer ${ }^{4}$.

Frequent use of areca nut with or without tobacco have adverse effect on soft and hard part of the oral cavity ${ }^{5}$. Areca nut damage the connective tissue of the oral cavity causing fibrosis that is a premalignant stage of cancer ${ }^{6}$. In India population of 5 million is suffering with $\mathrm{OSMF}^{7}$. However, alcohol and cigarette smoking with betel quid are also leading cause of oral cancer $^{\circ}$. In Pakistan, all new cancer cases of oral cavity and lips are $8.6 \%$ that leads to $7.2 \%$ deaths ${ }^{9}$. The chronically progressive disease of upper digestive tract of submucosa that is OSMF caused by the aggressive use of areca nut ${ }^{10}$. Where clinical features are decreased mouth opening, blanching and stiffness of the oral mucosa, burning sensation and hypomobility of soft palate and tongue diminish the action of eating and swallowing ${ }^{6}$.

Areca nut use is not limited to Asia, but its usage has broken the limits through North America and other European countries, which is due to lack of awareness of the harmful effect on their general and oral health. Areca nut is the basic part of betel quid. People think that it is healthy and consume it as a mouth freshener, and energizer ${ }^{11}$. In India and Pakistan, people chew areca nut with, slaked lime, catechu, condiments and Sugar flavored masala in traditional ceremonies ${ }^{8}$. However, adding up tobacco in the same mixture become mainpuri, Gutka, pan parag and other tobacco-based products available in market ${ }^{1}$. Commercially manufactured dry areca mixture contains alkaloids (Arecoline), which are responsible for stimulating malignant changes in the oral tissue ${ }^{12}$. A study revealed that in Nepal 14-18 years old adolescents were routinely chew areca nut were 
(30.4\%), Supari (Chaliya) (81.6\%), and (08.0\%) gutka $^{13}$. A recent report related Karachi city showed that $40 \%$ people were facing dental problems, pain, sensitivity and impairment of tooth resulting difficulty in eating ${ }^{14,15}$.

Additionally, report explained that consumption of 6-10 sachets of areca nut daily exposed the severity of OSMF $;{ }^{10}$ similarly whether consuming betel quid with or without tobacco or other products such as gutka and Mainpuri ${ }^{7}$. It is frightening for societies that the youth involvement in eating areca nut, leads them to miserable life ending by causing vigorous local or general health issues. It is suggested to introduce sociocentric plans regarding health promotion and knowledge along with modification in living style can help to evade this menace ${ }^{10}$. The study aimed to determine oral health effects of areca nut with better understanding of oral sub-mucosal fibrosis caused by areca nut amongst nursing students. The rational of this study is to evaluate oral health issues such as oral sub mucous fibrosis related to areca nut and its products amongst young nursing students. Also, this will assist students to develop a better understanding of the malignant outcomes of such products. Consequently, they will avoid eating areca nut and as health care professionals they might educate patients in hospitals to prevent consuming such products.

\section{METHODOLOGY}

A descriptive cross-sectional study was conducted to gather information from students of three institutes, namely School of Nursing Sir C.J Psychiatry Hospital, School of Nursing Liaquat University Hospital Hyderabad / Jamshoro and Jamshoro College of Nursing from November 2018 - January 2019.

The overall study population of three nursing schools was 500 among which sample size obtained was 380 by using least prevalence. Sample size was calculated according to the formula $n=z^{2}(p x q) / e^{2}$. The prevalence was taken as 55 percent ${ }^{10}$. Through simple random method 127 students from each study setting were surveyed. The instrument was structured questionnaire that contained two sections i.e. Section A for demographic characteristics and Section B illustrating 21 items concerning usage of areca nut, reasons of chewing, effect on oral health of users and its awareness among users and non-users to assess if it is the only cause of Oral sub-mucous fibrosis. The instrument was adopted with permission ${ }^{15}$.

Tool was slightly modified according to study requirement and validated. Piloting of research tool was conducted on $10 \%$ of total population who were not subjected in the study. Respondents were Nursing students of all years from various disciplines including diploma in General Nursing and Post RN BSN respectively; who consented in writing and data was obtained on same day at their respective settings followed by obtaining approval from Ethical Review Committee Liaquat University of Medical and Health Sciences, Jamshoro and from the authorities of study settings.

The inclusion criteria for taking part in study was principally participants' willingness, both genders of all years of nursing students; excluding individuals with ages less than 16 or more than 40 years and who voluntarily refused to take part. Total 380 questionnaires were distributed and returned with $100 \%$ participation rate in the study. Chi- square test was used for differences in frequencies among areca nut users and oral health effects after using gender variables. A significance level set at $P \leq 0.05$.

\section{RESULTS}

Total of 380 nursing students $(n=380)$ were surveyed in this study and there were no refusals, hence the participation rate was $100 \%$. Out of 380 students 203 (53.4\%) were male and 177 (46.6\%) female. The age range of nursing students was $16-40$ years with the mean age of 23.4 years and SD \pm 5.7 years as shown (Table I).

TABLE I: SHOWING AGE OF PARTICIPANTS

\begin{tabular}{|l|c|c|c|c|c|}
\hline Age (years) & Male & Female & Total & Mean & S.D \\
\hline $16-20$ & 76 & 83 & 159 & & \\
\cline { 1 - 4 } $21-25$ & 44 & 40 & 84 & & \\
\cline { 1 - 4 } $26-30$ & 66 & 25 & 91 & \multirow{2}{*}{23.4} & \multirow{2}{*}{ \pm 5.7} \\
\cline { 1 - 4 } $31-35$ & 12 & 22 & 34 & & \\
\cline { 1 - 4 } $35-40$ & 05 & 07 & 12 & & \\
\cline { 1 - 4 } Total & 203 & 177 & 380 & & \\
\hline
\end{tabular}

* Gender distribution of participant Cross tabulation In this study majority of respondent fall under age group of 16-20 years with the frequency 159. In this study the participants were nursing students including both Basic (Diploma Nursing) and Post RN BS Nursing.

In this study $45.2 \%$ (172) chewers claimed that areca nut enhances the capacity to concentrate while $51.5 \%$ (192) participants claimed of increasing in blood glucose levels, additionally, it was observed that $45.30 \%$ students who were consuming areca nut with other product such as betel quid, mainpuri, gutka and pan parag as shown in Figure $\mathbf{I}$. 
Erum Aftab, Erum Khan, Farah Anil, Rahmatullah Vinjhar

FIGURE I: DEPICTING THE PATTERN OF ARECA NUT PRODUCTS AMONG ARECA NUT USERS WITH THE BETEL QUID TO BE THE MOST POPULAR DERIVATIVE

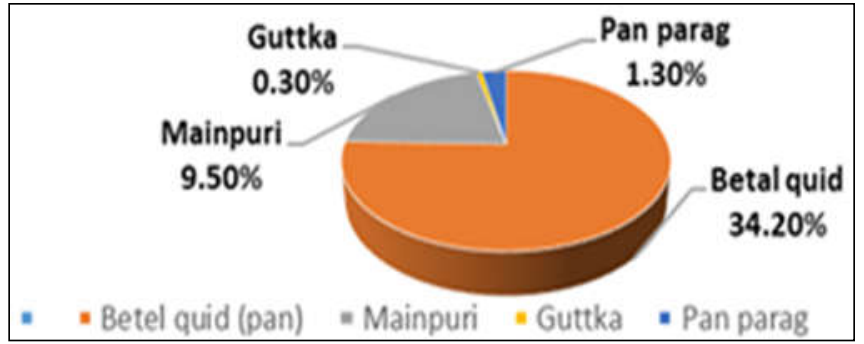

There were 164 (43\%) students with oral health problems and results were statistically different between gender categories. The proportion of respondents claiming areca nut is harmful for oral health was $322(84 \%)$.

Data illustrated the frequency of male students of chewing areca nut was higher in numbers as compare to female students Table II.

TABLE II: DEPICTING THE GENDER DISTRIBUTION OF PARTICIPANT THROUGH CROSS TABULATION

\begin{tabular}{|l|c|c|c|}
\hline \multicolumn{4}{|c|}{ Chewing Areca Nut } \\
\hline Response & Male & Female & Total \\
\hline Yes & 179 & 133 & 312 \\
\hline No & 24 & 44 & 68 \\
\hline Total & 203 & 177 & 380 \\
\hline
\end{tabular}

Subsequently, the difference of chewing reasons that influenced the consumption of areca nut and its products was statically dissimilar among its users as presented in Figure II.

FIGURE II: ILLUSTRATING THE COMMON REASONS OF CONSUMING ARECA NUT AMONG NURSING STUDENT

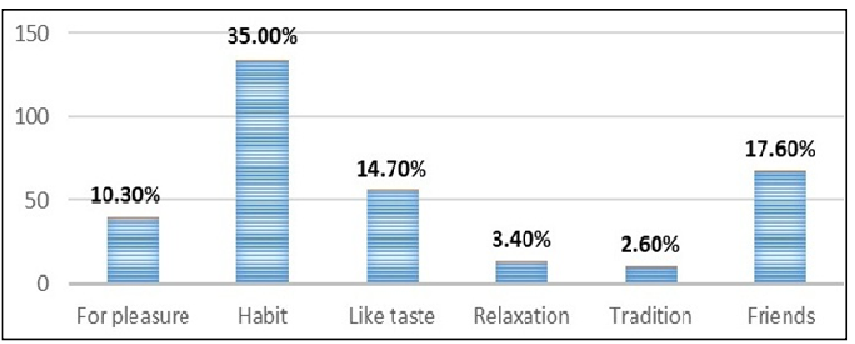

Despite of having oral health problems 170 (45\%) did not seek any medical assistance. The most responded reasons for chewing areca nut found in descending order from habit, friends, like taste and seek pleasure respectively. Oral changes observed and recorded.
Particulars of statistics also revealed that the number of respondents suffering from altered oral health problems caused by aggressive use of areca nut were less obvious as shown in Table \& Figure III.

\section{FIGURE III: SHOWING THAT THERE WERE ABOUT $30 \%$ OF RESPONDENTS WHO WERE AFFECTED WITH ORAL LESIONS}

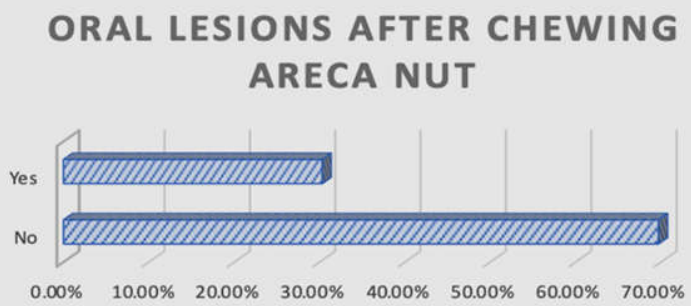

Approximately there were $13 \% \quad(n=51)$ non-user of areca nut but still oral lesions and cavities were evident. Most respondents recognized a relationship between areca nut chewing and mouth cancer; along with perception of majority of students that mouth cancer can be prevented in similar way. The frequency of user and non-user were $312(82.10 \%)$ and $68(17.90 \%)$ having awareness regarding medical conditions due to chewing arena nut.

TABLE III: DEPICTING ALTERED ORAL HEALTH RELATED PROBLEMS WHICH WERE SIGNIFICANTLY LESS FREQUENT

\begin{tabular}{|c|c|c|c|}
\hline $\begin{array}{l}\text { Problems after } \\
\text { chewing areca }\end{array}$ & Response & Frequency & Percent \\
\hline \multirow{2}{*}{ Burning sensation } & No & 229 & $60.30 \%$ \\
\hline & Yes & 151 & $39.70 \%$ \\
\hline \multirow{2}{*}{$\begin{array}{l}\text { Limited mouth } \\
\text { opening }\end{array}$} & No & 374 & $98.40 \%$ \\
\hline & Yes & 6 & $1.60 \%$ \\
\hline \multirow{2}{*}{ Problem in chewing } & No & 368 & $97 \%$ \\
\hline & Yes & 12 & $3 \%$ \\
\hline \multirow{2}{*}{$\begin{array}{l}\text { Blanching of oral } \\
\text { cavity }\end{array}$} & No & 377 & $99.20 \%$ \\
\hline & Yes & 3 & $0.80 \%$ \\
\hline \multirow{2}{*}{ Vesical and Ulcer } & No & 368 & $97 \%$ \\
\hline & Yes & 12 & $4 \%$ \\
\hline \multirow{2}{*}{ Loss of appetite } & No & 367 & $96 \%$ \\
\hline & Yes & 13 & $4 \%$ \\
\hline \multirow{2}{*}{ Cavities } & No & 234 & $62 \%$ \\
\hline & Yes & 146 & $38 \%$ \\
\hline \multirow{2}{*}{$\begin{array}{l}\text { Problem in } \\
\text { deglutition }\end{array}$} & No & 376 & $98 \%$ \\
\hline & Yes & 4 & $2 \%$ \\
\hline \multirow{2}{*}{$\begin{array}{l}\text { Plaque/Tartar } \\
\text { accumulation on } \\
\text { tooth surface }\end{array}$} & No & 378 & $99 \%$ \\
\hline & Yes & 2 & $1.00 \%$ \\
\hline
\end{tabular}




\begin{tabular}{|l|l|r|r|}
\hline \multirow{2}{*}{ Dry mouth } & No & 369 & $97 \%$ \\
\cline { 2 - 4 } & Yes & 11 & $3.00 \%$ \\
\hline \multirow{2}{*}{ Tooth staining } & No & 256 & $67.36 \%$ \\
\cline { 2 - 4 } & Yes & 124 & $32.60 \%$ \\
\hline \multirow{2}{*}{ Bleeding gums } & No & 376 & 98.94 \\
\cline { 2 - 4 } & Yes & 4 & $1.06 \%$ \\
\hline
\end{tabular}

The frequency of consuming areca nut made products decreases as the age's increases this negative effect was determined by using Chi-square as a statistical model. Chi-square test was also performed among areca nut users and other variables. The relation between these variables was not found significant, $X^{2}$ $(\mathrm{N}=380)=10.937$ at $\mathrm{p}<0.05$.

\section{DISCUSSION}

The study concentrated to explore the frequency pattern of areca nut chewing, especially while observing the chewing of areca nut amongst students of different nursing institutes of Hyderabad and Jamshoro districts in Sindh, who primarily belongs to healthcare profession, and possess knowledge of harmful effects of areca nut usage on oral health.

Being health care provider while noticing the upcoming nurses' generation involve in this nuisance habit provided motivation to conduct this study. The frequency of areca nut usage in this study was 312 $(82.10 \%)$ and the results were comparable to another study conducted in Karachi ${ }^{10}$. Like students of other health professions, nursing students were also found frequent areca nut users as habit with minimum oral health effects as contrast with other study ${ }^{17}$.

In our study while working with assessment of awareness regarding oral health effects of areca nut, a comparative survey that was carried out in Lahore amongst undergraduate dental students found that dental students had better knowledge and information regarding the causal agents, clinical presentation of oral cancer ${ }^{18}$. We have found that consumption chewing habit of areca nut made products decreases as the age's increases while there was no difference in both sexes. These results were contradicted with another study conducted by Leghari MA $2016^{15}$, where with increase in age consumption was increasing.

Recognized oral health effects of areca nut found in our study among nursing students as of most are burning sensation, cavities and tooth staining which are similar to another study which expresses history of consuming areca nut and it's made products on daily basis which cause burning sensation while intake zesty foods ${ }^{6}$.

For the response on duration of areca chewing in

years had insignificant association with OSMF development. However, the daily consumption frequency was significant with individuals consuming more than 5 packets per day showing increased severity which is similar with the findings of Hosein $M$ $2015^{10}$. Another study indicate 174 participants were regular quid chewer and having positive results of salivary pooling because of affected mucosal surfaces and also noticed that the quid is not the only cause of OSMF. In our study 178 nursing student's response that areca nut stimulates the salivation which is similar with the finding of Arakeri $\mathrm{G}$ et $\mathrm{al}^{19}$.

Our study determines that harmful effects caused by areca nut on tooth decay and buccal mucosa lesions developed at chewing side. The results showed same effects in another study ${ }^{20}$. In present study areca nut users and non-users both having problem on buccal mucosa, it is comparable with two more studies that divulge OSMF clinically imitate conditions like vitamin $\mathrm{B}_{12}$ and iron deficiency anemia usually cause such as, blanching, burning sensation, and swallowing difficulties these effects provide a route to malignancy ${ }^{21-23}$.

According to the study conducted by Alam BF et al. ${ }^{17}$ the consumption of areca and its products with or without tobacco has harmful effects on oral health. Both soft and hard part of the oral cavity affected from the areca nut consumption. Habitual eaters of areca products were found in our study to have lesions and changes in oral mucosa as compare to other study conducted in Pakistan.

Random sampling method was used although the sample size was not enough, the reason for the selection was that there was no previous history of data collection and survey of nursing students either bachelors or basic program on areca and other associated (chewing) products and their effects in developing OSMF.

\section{CONCLUSION}

Results of the current study showed higher prevalence of areca nut usage among nursing students in both genders, where male student's frequency was slightly higher than female. Moreover, peer influence was pronounced in developing areca nut chewing habit and half of subjects were aware of its harm full effects on oral health. Although, users of areca-nut made products with betel quid admitted to chew mainpuri as well but no significant difference was found. There is a critical need of action plans for implementation of law against areca-nut products supplies to prevent oral cancer in future.

Ethical permission: Dean Faculty of Community Medicine \& Public Health Sciences, Liaquat University of Medical \& Health Sciences Letter No. 
LUMHS/CM/Dean/40, Dated: 19-03-2019.

Conflict of interest: Authors of the study have no conflict of interest to declare.

Funding: There was no any funding agency.

\section{REFERENCES}

1. Jayakrishnan $R$, Geetha $S$, Mohanan Nair JK, Thomas G, Sebastian P. Tobacco and alcohol use and the impact of school based antitobacco education for knowledge enhancement among adolescent students of Rural Kerala, India. J Addict. 2016; 2016: 9570517. doi: 10.1155/2016/ 9570517.

2. World Health Organization. WHO global report on trends in prevalence of tobacco smoking 2015. WHO; 2015.

3. Salam H, Ahmed S, Wahid M, Irshad M. Pattern of presentation for oral submucous fibrosis. Pak Oral Dent J. 2016; 36(2): 217-20.

4. Niaz K, Maqbool F, Khan F, Bahadar H, Ismail Hassan F, Abdollahi M. Smokeless tobacco (paan and gutkha) consumption, prevalence, and contribution to oral cancer. Epidemiol Health. 2017; 39: e2017009. doi: 10.4178/epih.e2017009.

5. Das T, Mahato B, Chaudhuri K. Effect of areca nut on rabbit oral mucosa: evidence of oral precancerous condition by protein expression and genotoxic analysis. Oral Sci Int. 2018; 15(1): 7-12. doi: 10.1016/S1348-8643(17)30021-6.

6. Hameed F, Ali I, Khan Z, Aslam MA, Hafeez N, Haider SM, et al . Estimation of Serum Iron in Oral Submucous Fibrosis Patients and its Comparison with Healthy Controls. Pak J Otolaryngology. 2015; 31(2): 1-26.

7. Prabhu RV, Prabhu V, Chatra L, Shenai $P$, Suvarna N, Dandekeri S. Areca nut and its role in oral submucous fibrosis. J Clin Exp Dent. 2014; 6 (5): e569-e575. doi:10.4317/jced.513 18

8. National Cancer Institute - Centers for Disease Control and Prevention. Smokeless tobacco and public health: A global perspective. $\mathrm{NCl}, \mathrm{CDC} \&$ Prev, US-HHS, Bethesda; 2014. Available from: https://cancercontrol.cancer.gov/brp/tcrb/globalperspective/Smokeless TobaccoAnd PublicHealth.pdf.

9. Sarwar MR, Saqib A. Cancer prevalence, incidence and mortality rates in Pakistan in 2012. J Cogent Med. 2017; 4(1): 1288773. doi:10.1080/2331205X.2017.1288773.

10. Hosein M, Mohiuddin S, Fatima N. Association Between Grading of Oral Submucous Fibrosis With Frequency and Consumption of Areca Nut and Its Derivatives in a Wide Age Group: A Multi-centric Cross Sectional Study From Karachi,
Pakistan. J Cancer Prev. 2015; 20(3): 216-22. doi: 10.15430/JCP.2015.20.3.216.

11. Banerjee SC, Ostroff JS, Bari S, D'Agostino TA, Khera M, Acharya S, et al. Gutka and Tambaku Paan use among South Asian Immigrants: A focus group study. J Immigr Minor Health. 2014; 16(3): 531-39. doi: 10.1007/s10903-013-9826-4.

12. Mathew $P$, Austin RD, Varghese SS, Kumar M. Role of areca nut and its commercial products in oral submucous fibrosis - A review. J Adv Med Dent Sci Res. 2014; 2(3): 192-200.

13. Wazir SS, Arora P, Kapoor S, Jayam R, Sharma $\mathrm{S}$, Rastogi T. Prevalence of areca nut chewing habit among high school children of Parsa district of Nepal. J Oral Biol Craniofac Res. 2017; 7(3): 161-6. doi: 10.1016/j.jobcr.2016.10.008.

14. Khan MS, Bawany FI, Shah SR, Hussain M, Arshad $\mathrm{MH}$, Nisar N. Comparison of knowledge, attitude and practices of areca nut users in two socioeconomic areas of Karachi. J Pak Med Assoc. 2013; 63(10): 1319-25.

15. Leghari MA, Ali S, Maqbool S. The prevalence of use of areca nut on its effect on oral health in school going children in Gadap town, Malir, Karachi, Pakistan. World J Dent. 2016; 7(1): 6-9. doi:10.5005/jp-journals-10015-1354.

16. Shah SM, Merchant AT, Luby SP, Chotani RA. Addicted school children: Prevalence and characteristics of areca nut chewers among primary school children in Karachi, Pakistan. J Paediatr Child Health. 2002; 38(5): 507-10.

17. Alam BF, Anwar M, Nayab T, Azfar M, Shaikh P, Shakeel A. Oral Cancer Awareness among Medical \& Dental Students of Bahria University Medical and Dental College. J Pak Dent Assoc. 2018; 27(04): 172-80. doi: 10.25301/ JPDA.274.172.

18. Yadav A, Kumar L, Misra N, Deepak U, Shiv Kumar GC. Estimation of serum zinc, copper, and iron in the patients of oral submucous fibrosis. Natl J Maxillofac Surg. 2015; 6(2): 190-3. doi: 10.4103/0975-5950.183851.

19. Arakeri G, Colbert S, Patil SG, Hale B, Merkx MA, Brennan PA. Salivary pooling: is it specific to particular regions in oral submucous fibrosis? $\mathrm{Br} J$ Oral Max Surg. 2015; 53(3): 275-8. doi: 10.1016/j.bjoms.2014.12.009.

20. Anand R, Dhingra C, Prasad S, Menon I. Betel nut chewing and its deleterious effects on oral cavity. $J$ Cancer Res Ther. 2014; 10(3): 499-505. doi: 10.4103/0973-1482.137958.

21. Karthik H, Nair P, Gharote HP, Agarwal K, Bhat GR, Rajaram DK. Role of hemoglobin and serum iron in oral submucous fibrosis: A clinical study. Sci World J. 2012; 2012: 254013. 
doi:10.1100/2012/254013.

22. Chang JY, Wang YP, Wu YC, Cheng SJ, Chen $\mathrm{HM}$, Sun A. Blood profile of oral mucosal disease patients with both vitamin B12 and iron deficiencies. J Formos Med Assoc. 2015; 114(6):
532-8. doi:10.1016/j.jma.2015.03.002.

23. Baig S, Rubab Z, Farooq W. Molecular Pathogenesis of Chewable Tobacco. J Coll Physicians Surg Pak. 2018; 28(5): 381-5. doi:10.29271/jcpsp.2018.05.381.

AUTHOR AFFILIATION:

Erum Aftab (Corresponding Author)

Peoples Nursing School

(PNS), LUMHS, Jamshoro, Sindh-Pakistan.

Email: rattiisaacraja@gmail.com

Dr. Erum Khan

Assistant Professor, Institute of Dentistry

LUMHS, Jamshoro, Sindh-Pakistan.

\section{Farah Anil}

PNS, LUMHS, Jamshoro, Sindh-Pakistan.

\section{Rahmatullah Vinjhar}

PNS, LUMHS, Jamshoro, Sindh-Pakistan. 